\title{
Bone health in women with a history of gestational diabetes or obesity
}

\author{
Engberg, Elina
}

2020-04

Engberg , E , Koivusalo , S B , Huvinen , E \& Viljakainen , H T 2020 , ' Bone health in women with a history of gestational diabetes or obesity ' , Acta Obstetricia et Gynecologica Scandinavica, vol. 99 , no. 4 , pp. 477-487 . https://doi.org/10.1111/aogs.13778

http://hdl.handle.net/10138/323656

https://doi.org/10.1111/aogs.13778

unspecified

acceptedVersion

Downloaded from Helda, University of Helsinki institutional repository.

This is an electronic reprint of the original article.

This reprint may differ from the original in pagination and typographic detail.

Please cite the original version. 


\section{Bone health in women with a history of gestational diabetes or obesity}

Elina Engberg ${ }^{1,2}$, Saila B. Koivusalo ${ }^{3}$, Emilia Huvinen ${ }^{3}$, Heli Viljakainen ${ }^{1,4}$

${ }^{1}$ Folkhälsan Institute of Genetics, Folkhälsan Research Center, Biomedicum Helsinki, Helsinki, Finland

${ }^{2}$ Department of Sports and Exercise Medicine, Clinicum, Faculty of Medicine, University of Helsinki, Helsinki, Finland

${ }^{3}$ Department of Obstetrics and Gynecology, University of Helsinki and Helsinki University Hospital, Helsinki, Finland

${ }^{4}$ Department of Food and Environmental Sciences, University of Helsinki, Helsinki, Finland

\section{Corresponding author:}

Elina Engberg

Folkhälsan Research Center, Topeliuksenkatu 20, 00250 Helsinki, Finland

Email: elina.engberg@helsinki.fi

Elina Engberg ORCID: 0000-0002-8713-5607

Saila B. Koivusalo ORCID: 0000-0002-9482-9826

Emilia Huvinen ORCID: 0000-0003-2788-1947

Heli Viljakainen ORCID: 0000-0002-7486-3437

\section{Conflicts of Interest}

None 


\section{Funding:}

This study was funded by Ahokas Foundation, the Finnish Foundation for Cardiovascular Disease, Academy of Finland, Special state subsidy for health science research of Helsinki University Hospital (HUH), Samfundet Folkhälsan, Finska Läkaresällskapet, Juho Vainio Foundation, Viipuri Tuberculosis Foundation, The Finnish Diabetes Research Foundation, State Provincial Office of Southern Finland, Health Promotion Grant (Ministry of Social Affairs and Health) EU H2020-PHC-2014-DynaHealth Grant No. 633595, The Social Insurance Institution of Finland and Päivikki and Sakari Sohlberg Foundation. 


\section{ABSTRACT}

Introduction: Type 2 diabetes is associated with an increased risk of bone fractures.

However, bone health of women with a history of gestational diabetes (GDM) has received little attention. This cross-sectional study compares bone health between premenopausal women with and without a history of GDM, and examines factors associated with bone health in women with a history of GDM or obesity. Material and methods: We measured areal bone mineral density for total hip, lumbar spine and whole body, and total body fat percentage (fat $\%$ ) with dual-energy X-ray absorptiometry in 224 women. In addition, we measured bone characteristics of radius and tibia with peripheral quantitative computed tomography. Results: When compared to women without a history of GDM (mean age 39 [SD 5], BMI 35 [6], fat\% 48 [7]), women with a history of GDM (age 41 [4], BMI 31 [7], fat\% 43 [10]) had lower hip and whole body bone mineral densities, and inferior tibia outcomes. However, the differences in bone characteristics attenuated after controlling for age, height, BMI and fat\%. After controlling for age, height, BMI and smoking, physical activity and healthier diet were positively associated with bone outcomes, whereas fat\%, $\mathrm{HbA}_{1 \mathrm{c}}$ and screen time were negatively associated with bone outcomes. Particularly, fat\% showed independent negative associations with whole body bone mineral density and several tibia and radius characteristics. Conclusions: Fat\% is associated with adverse bone health, independently of BMI, in women with a history of GDM or obesity. Promoting healthy lifestyle and reducing fat\% in women with a history of GDM or obesity could improve bone health and prevent future fractures.

\section{Key words}

DXA; pQCT; bone mineral density; body fat; gestational diabetes mellitus; women
Abbreviations:
BMD bone mineral density
DXA dual-energy X-ray absorptiometry
GDM gestational diabetes mellitus
pQCT peripheral quantitative computed tomography
T2D type 2 diabetes
RADIEL the Finnish Gestational Diabetes Prevention Study
BMI body mass index 


\section{Key Message}

Bone fractures in women with a history of gestational diabetes or obesity could possibly be prevented by promoting healthy lifestyle leading to reduced fat percentage. 


\section{INTRODUCTION}

Along with obesity, the prevalence of type 2 diabetes (T2D) is increasing worldwide ${ }^{1,2}$. In addition to several other complications, T2D is associated with an increased risk of bone fractures ${ }^{3,4}$. This is of importance because fractures impair quality of life, induce disability, increase health care costs and even mortality ${ }^{5-8}$. The increased risk of fractures in T2D is caused by diabetes-associated alterations in bone quality, defined as diabetoporosis 9 . Diabetes-associated alterations in bone are proposed to be related to the duration of T2D, impaired glycemic control and chronic inflammation ${ }^{4,10,11}$. However, it is unclear how early the diabetes-induced alterations in bone health occur.

Alarmingly, also the prevalence of gestational diabetes mellitus (GDM) is increasing worldwide ${ }^{12}$. GDM, defined as impaired glucose tolerance with onset or first recognition during pregnancy, is a major risk factor for future T2D ${ }^{13,14}$. Although GDM usually resolves after giving birth, women with GDM have up to a 7-fold increased risk for T2D during the next five to ten years ${ }^{14}$. Women with a history of GDM may present with prediabetes, which means that their blood glucose level may be higher than normal but lower than the diagnostic threshold for T2D. Several healthy lifestyle factors improve bone health, whereas physical inactivity, a nutrient-poor-energy-dense diet and smoking deteriorate bone health ${ }^{15-19}$. Studies suggest that women at risk for GDM have poorer diet quality and low levels of physical activity ${ }^{20-22}$, which could affect their bone health.

There is a lack of studies examining bone health of women with a history of GDM. Furthermore, identifying factors related to bone health in women at risk for T2D should be addressed. Knowledge on the early changes in, and factors associated with bone quality could be helpful in developing preventive strategies for diabetes-associated alterations in bone. To the best of our knowledge, this study examines for the first time the bone health of women with a history of GDM and/or obesity. We aim to 1) compare bone health between women with and without a history of GDM, and 2) identify factors associated with bone health among women with a history of GDM or obesity.

\section{MATERIAL AND METHODS}

\subsection{Study design}


This cross-sectional study examines follow-up data of the Finnish Gestational Diabetes Prevention Study (RADIEL). The RADIEL study is a randomized controlled intervention trial conducted in four maternity hospitals in Finland between the years 2008 and 2014. The main objective of the RADIEL study was to assess the efficacy of a lifestyle intervention in preventing GDM among women at high risk for the disease, i.e. women with a history of GDM and/or prepregnancy obesity ${ }^{23}$. This cross-sectional analysis utilizes the follow-up data of the RADIEL study collected between September 2016 and March 2017, and treats the subjects as a cohort of women with a history of GDM or obesity.

\subsection{Participants}

Eligible participants for the original RADIEL study were women either planning pregnancy or pregnant at $<20$ weeks of gestation, $\geq 18$ years old, and with either a history of GDM and/or prepregnancy body mass index (BMI) $\geq 30 \mathrm{~kg} / \mathrm{m}^{2}$. The women were at high risk for GDM, since high BMI and GDM in a previous pregnancy are major risk factors for GDM ${ }^{24,25}$. The detailed inclusion and exclusion criteria for the RADIEL study are described elsewhere ${ }^{23}$. We invited the women from the Helsinki metropolitan area who gave birth and had at least one RADIEL study visit during pregnancy to a follow-up about six years after the RADIEL index delivery. The 6-year follow-up included bone health and anthropometric measurements, and the women completed a questionnaire on health- and lifestyle-related factors. In this analysis, we include the women who participated in the 6-year follow-up.

\subsection{Measurements}

In this study, a history of GDM refers to women having a diagnosis of GDM either before participating in the RADIEL study, or in the index pregnancy of the RADIEL study. Thus, GDM was diagnosed on average six years (range 3-8 years) before the bone measurements. GDM diagnosis prior to the RADIEL study was verified from the hospital registries. GDM in the index pregnancy of the RADIEL study was defined as one or more pathological glucose value in a 2-hour 75g oral glucose tolerance test (OGTT) either in the first or second trimester of pregnancy, with the diagnostic thresholds of fasting plasma glucose $\geq 5.3 \mathrm{mmol} / \mathrm{L}, 1$-hour value $\geq 10.0 \mathrm{mmol} / \mathrm{L}$, and 2 -hour value $\geq 8.6 \mathrm{mmol} / \mathrm{L}$. At the 6 -year follow-up, the participants' glycosylated hemoglobin $\left(\mathrm{HbA}_{1 \mathrm{c}}\right)$ was measured to assess blood glucose level over time. A study nurse measured the subjects' height and weight, and BMI was calculated. In addition, we measured total body fat percentage (fat $\%$ ) with dual-energy X-ray absorptiometry (DXA). The women reported dates of their deliveries, osteoporosis diseases 
(conditions that last for a long time and require ongoing medical attention and/or limit activities of daily living), medication (regular or irregular; for example for pollen allergies), prior fractures and whether they have osteoporosis (a health condition that weakens bones, making them fragile and more likely to break) in the immediate family with a questionnaire.

We assessed lifestyle behaviors with a questionnaire. The women answered questions on supervised and unsupervised physical activity during leisure-time, commuting physical activity, and screen time during leisure-time. Based on the answers, we report participants' supervised leisure-time physical activity, total leisure-time physical activity, total physical activity, and leisure-time screen time in minutes per day. We assessed food intake with a 50item food frequency questionnaire (FFQ) with additional questions on special diets, quality of dietary fats and eating lunch during the preceding week. We created a Healthy Eating Index (HEI) based on seven FFQ items regarding whole grains, quality of dietary fat, red meat, dairy products, fish and vegetables/fruits/berries. The maximum score in HEI is 35, with a higher score indicating healthier and more balanced Nordic diet ${ }^{26}$. In addition, the women answered a question on smoking habits (yes, no, previously).

We measured areal bone mineral density (BMD; $\mathrm{g} / \mathrm{m}^{2}$ ) for total hip, lumbar spine (L1-L4) and whole body with DXA (Lunar Prodigy Advance DXA; GE Healthcare; Madison, WI) in subjects with weight $<160 \mathrm{~kg}$. T-scores, standard deviations from the peak BMD, for each skeletal site was derived using a young Finnish female reference population ${ }^{27}$. The measurements were calibrated daily with a spine phantom. Reproducibility of DXA measurement for total body is: $\mathrm{BMD}=0.85 \%$, bone mineral content $=0.45 \%$ and bone area $=$ $0.78 \%{ }^{28}$.

In addition, we measured bone geometry and volumetric density of radius and tibia with peripheral quantitative computed tomography (pQCT) (XCT-2000; Stratec; Pforzheim; Germany; software version 6.20). The repeatability of the pQCT was evaluated with measurements of phantom provided by the manufacturer. We measured radius at distal (4\%) and proximal (66\%) sites, and tibia at distal (4\%) and diaphyseal (33\%) sites. We report the following variables for distal sites of radius and tibia: total bone mineral content (BMC; $\mathrm{g} / \mathrm{cm})$, total cross-sectional area $\left(\right.$ TotCSA $\left.; \mathrm{mm}^{2}\right)$, total volumetric density (TotDen; $\mathrm{mg} / \mathrm{cm}^{3}$ ) and trabecular volumetric density $\left(\right.$ TrabDen; $\left.\mathrm{mg} / \mathrm{cm}^{3}\right)$. For the proximal site of radius and the diaphyseal site of tibia, we report BMC, polar strength strain index (SSIPOL; $\mathrm{mm}^{3}$ ), TotCSA, TotDen, cortical volumetric density $\left(\right.$ CortDen $\mathrm{mg} / \mathrm{cm}^{3}$ ) and cortical cross-sectional area (CortCSA; $\left.\mathrm{mm}^{2}\right)$. 


\subsection{Statistical analyses}

We examined normal distribution of the variables in the whole cohort and separately for the women with and without a history of GDM visually and with the Shapiro-Wilk test. We applied logarithmic transformations if needed. We compared the differences in anthropometric, health, lifestyle and bone characteristics between the women with and without a history of GDM with the Chi-square test, the Mann-Whitney U test or the independent sample T-test, when appropriate. Moreover, we identified variables associated with bone characteristics with the Spearman's rank-order correlation, adjusting for variables commonly associated with bone health (age, height, BMI and smoking status). We considered the variables associated with the bone characteristics as mediators and used those as additional covariates in further analyses. We performed the Multivariate analysis of covariance (MANCOVA) to evaluate the differences in the bone characteristics between women with and without a history of GDM when adjusting for age, height, BMI and fat\%. We performed the analyses for those with all the needed variables available, and report the numbers of subjects included in each analysis. We performed the statistical analyses with the SPSS 25.0 software program (SPSS Inc., Chicago, IL, USA) and considered a P value $<0.05$ as statistically significant.

\subsection{Ethical approval}

The RADIEL study is conducted in compliance with the World Medical Association Declaration of Helsinki — Ethical Principles for Medical Research Involving Human Subjects. Ethical approval was obtained from the Research Ethics Committees of the Hospital District of Helsinki and Uusimaa and the South-Karelia Central Hospital (HUS/42/2017, HUS/1268/2016), and the study protocol is registered at clinicaltrials.gov (NCT01698385). All participants provided a signed informed consent.

\section{RESULTS}

We invited 516 women from the original RADIEL study to the 6-year follow-up measurements, among which 229 participated. We were unable to perform the bone measurements to one woman who weighted $165 \mathrm{~kg}$, and four women were excluded from the RADIEL study or withdrew their consent, and thus not included this analysis. Finally, we included 224 women. 
Table 1 presents characteristics of the women with and without a history of GDM. The most common chronic diseases among the women were musculosceletal disease/symptoms $(n=16,7 \%)$ and asthma/allergy $(n=11,5 \%)$. Table 2 shows the bone charateristics of the women. Women with a history of GDM were older, and their BMI and fat\% were lower compared to women without a history of GDM. Moreover, women with a history of GDM had higher $\mathrm{HbA}_{1 \mathrm{c}}$ values. Other health or lifestyle characteristics did not differ between the groups.

Table 2 shows unadjusted differences in the bone characteristics between women with and without a history of GDM. Women with a history of GDM had lower hip BMD, whole body BMD, BMC in distal tibia, and lower BMC, SSIPOL, TotCSA and CortCSA in diaphyseal tibia. After adjusting for age, height, BMI and fat $\%$ these differences attenuated between the groups. However, the difference became significant for SSIPOL in proximal radius $(\mathrm{P}=0.018)$, with lower adjusted means $(274.3$, standard error of the mean [SEM] 4.6) for women with a history of GDM when compared to women without a history of GDM (294.0, SEM 6.5). Based on the T-score cut-off values, none of the participants had osteoporosis (T-score of -2.5 or lower). Nine $(6 \%)$ of the women with a history of GDM and four $(5 \%)$ of the women without a history of GDM had osteopenia (T-score of -1 to -2.5$)$ in at least one of the bone sites measured with DXA (hip, lumbar spine or whole body). The difference between the groups in osteopenia was not statistically significant.

Table 3 presents the associations of the bone characteristics with health- and lifestylerelated factors. In summary, after adjusting for age, height, BMI and smoking status (i.e. typical factors affecting bone health), fat\% showed the strongest correlations and was inversely associated with most of the bone characteristics. Other factors associated with bone characteristics were $\mathrm{HbA}_{1 \mathrm{c}}$, supervised leisure-time physical activity, total leisure-time physical activity, total physical activity, screen time and HEI. Years since last delivery were not associated with bone characteristics (Table 3).

We additionally examined the crude correlations between fat $\%$ and other factors associated with bone health, and detected a positive association between fat $\%$ and $\mathrm{HbA}_{1 \mathrm{c}}\left(\mathrm{r}_{\mathrm{s}}=\right.$ $0.272, \mathrm{P}<0.001$ ), and negative associations between fat $\%$ and supervised leisure-time physical activity $\left(\mathrm{r}_{\mathrm{s}}=-0.216, \mathrm{P}=0.001\right)$, total leisure-time physical activity $\left(\mathrm{r}_{\mathrm{s}}=-0.278, \mathrm{P}<\right.$ $0.001)$, total physical activity $\left(\mathrm{r}_{\mathrm{s}}=-0.214, \mathrm{P}=0.002\right)$ and $\mathrm{HEI}\left(\mathrm{r}_{\mathrm{s}}=-0.217, \mathrm{P}=0.002\right)$.

After adding fat $\%, \mathrm{HbA}_{1 \mathrm{c}}$, supervised leisure-time physical activity, screen time and HEI as covariates for each other, fat $\%$ continued showing independent inverse associations with 13 out of the 23 bone characteristics (Table 4). Supervised leisure-time physical activity 
showed positive independent associations with two distal tibia characteristics, whereas HEI showed positive independent associations with two diaphyseal tibia characteristics. $\mathrm{HbA}_{1 \mathrm{c}}$ and screen time were not independently associated with the bone characteristics (Table 4).

\section{DISCUSSION}

This study examined for the first time the bone health of women with a history of GDM and/or obesity. The results showed that woman with a history of GDM did not have adverse bone characteristics compared to women without a history of GDM but with excess weight after adjustments for age, height, BMI and fat $\%$. Furthermore, fat $\%$, physical activity and diet were associated with bone health in women with a history of GDM or obesity. Fat\% showed the strongest correlations and was negatively associated with several bone characteristics, independently of BMI and other health-related factors.

Our cohort consists of a unique sample of 224 high-risk women who had either a history of GDM (with or without obesity) or prepregnancy obesity, which resulted in considerable variation in BMI, fat\% and lifestyle factors. Nevertheless, most of the women were currently obese and the mean fat $\%$ was high (44\%). Among the women, 146 had a history of GDM but the current $\mathrm{HbA}_{1 \mathrm{c}}$ values of the women were within the normal range in both groups.

Moreover, the women mostly had mild GDM: only about $30 \%$ of the women who participated in the RADIEL study and had GDM in the index pregnancy needed insulin or metformin treatment ${ }^{29,30}$. This could be the reason for detecting no difference in bone health between women with and without a history of GDM after the adjustments. Another reason may be that the diabetes-induced alterations in bones do not yet occur in 40-year-old women but later in life. Furthermore, we did not have a control group of women with similar BMI to those with a history of GDM. However, based on the BMD T-scores, none of the women had osteoporosis and only 5-6\% had osteopenia in both groups, showing that also the women with a history of GDM had normal bone health when compared to reference values of young Finnish women. Nevertheless, the T-scores do not take into account BMI. Obesity protects from osteoporosis but the relative BMD for BMI may be lower in obese women compared to normal-weight women, which might contribute to a higher risk of fractures ${ }^{31}$.

One previous cohort study of 480 women, among which 96 had GDM, reported greater BMD losses from early pregnancy to third trimester of pregnancy in women with GDM when compared with women without GDM ${ }^{32}$. Within women with GDM, lower initial BMD values, higher fat accumulation and higher early-pregnancy BMI were associated with lower 
BMD loss. However, they did not control for BMI when examining the association between fat and bone loss. The authors concluded, in accordance with our findings, that although women with GDM had greater BMD loss than non-diabetic women, the difference was apparently explained by anthropometric factors rather than directly by the gestational diabetic state $^{32}$.

Our initial analyses showed that after controlling for typical factors affecting bone health (age, height, BMI and smoking status), fat $\%, \mathrm{HbA}_{1 \mathrm{c}}$, physical activity (especially supervised), screen time and food intake were associated with bone outcomes in women at risk for T2D. $\mathrm{HbA}_{1 \mathrm{c}}$ was associated with an increased bone fracture risk in a Chinese prospective study of 20,000 older people with T2D ${ }^{10}$, while sedentary lifestyle and obesity are suggested to contribute to the development of diabetoporosis ${ }^{9}$. Similarly to our results, another study showed that supervised leisure-time physical activity was positively associated with bone characteristics in normal-weight and obese young adults, and HEI in normal-weight young adults ${ }^{33}$. In the present study, higher fat\% was associated with lower physical activity levels and poorer diet, indicating an interaction between these factors. We assessed physical activity and diet with self-reported measures, which may be biased due to under- and overreporting. Therefore, the objectively measured fat $\%$ may be more accurate indicator of lifestyle behaviors.

Higher fat\% was negatively associated with whole body BMD and several radius and tibia outcomes even after adjusting for BMI, age, height, $\mathrm{HbA}_{1 \mathrm{c}}$, supervised physical activity, screen time and HEI. A previous study of 122 postmenopausal women with T2D compared DXA-derived BMD between women with prevalent vertebral fracture and those without osteoporosis or low-trauma fractures, and found lower BMD only at the distal radius in the vertebral fracture group ${ }^{34}$. The results suggest that distal radius may be the best site to assess fracture risk in T2D patients ${ }^{34}$, and are in accordance with another study reporting increased cortical porosity at the distal radius and tibia, as measured with PQCT in postmenopausal diabetic women who have fragility fractures ${ }^{35}$. Higher cortical porosity is reported in women with fractures (with and without diabetes) ${ }^{36-38}$, while studies in women with diabetes are controversial by showing both lower and higher cortical porosity ${ }^{39}$. Our results suggest that women with a history of GDM or obesity who have high fat $\%$ may be at risk for fractures in the future.

The previous research evidence regarding the relation between body fat and bone health in healthy populations is somewhat conflicting. Epidemiological studies indicate that high fat mass is positively correlated with high bone mass in both premenopausal and postmenopausal 
women ${ }^{40,41}$. Nevertheless, these studies did not adjust for the mechanical loading effects of body weight on bone mass. Similarly to our results, other studies have shown that after adjusting for body weight/BMI, the excess adipose tissue has a negative or no correlation with bone outcomes ${ }^{42,43}$. A study of 502 healthy subjects detected an inverse correlation between fat\% and lumbar spine BMD after adjusting for age and body weight in premenopausal women, but not in men or in postmenopausal women ${ }^{44}$. Furthermore, only among the premenopausal women, the women with the highest quartile of fat $\%$ had the lowest BMD even after adjusting for age, body weight, physical activity, alcohol use and smoking history ${ }^{44}$. Another previous cross-sectional study found that a relative bone strength index, a ratio of bone strength to load from body weight, was inversely associated with fat mass in 11-year-old girls, their premenopausal mothers and postmenopausal grandmothers, but remained relatively constant with increasing lean mass in the girls and premenopausal women ${ }^{45}$. The results indicate that the bone-strength deficit is attributable to increased fat mass, not to lean mass ${ }^{45}$. The results from these previous studies are in accordance with our results, and suggest that the beneficial effects of higher weight on bone, if any, do not compensate for the adverse effects of body fat. Possible mechanisms behind the adverse effects of body fat on bone health include obesity-related low-grade inflammation, which is associated with impaired bone characteristics ${ }^{46}$.

The strengths of our study include a cohort of over 200 women with a history of GDM and/or obesity. The women recruited for the RADIEL study represent the heterogenic population of women at high risk for GDM, because in addition to obese women also women with normal BMI who had a history of GDM were included. However, the women were initially recruited for a lifestyle intervention study and highly educated (32\% with an academic degree), and therefore may not be representative of the whole high-risk population 47. BMI did not differ between the women who initially participated in the RADIEL study and women who participated in the 6-year follow-up (mean $32 \mathrm{~kg} / \mathrm{m}^{2}$ in both) ${ }^{47}$. We measured fat\% with DXA, which is considered the most accurate measure of body composition and reliable also in obese adults ${ }^{48}$. We assessed bone health with two different densitometry techniques, which provide valuable evidence both for clinicians working with DXA and for researchers utilizing pQCT. We did not, however, measure bone turnover markers, which would have provided insight on the possible metabolic changes in bone. Limitations of the study include the cross-sectional study design, and therefore we cannot draw any conclusions on causality. Moreover, we lacked a control group of women without a history of GDM and normal BMI. 


\section{CONCLUSION}

Woman with a history of mild GDM did not have adverse bone health compared to women without a history of GDM but with excess weight after adjusting for confounding factors. Among women with a history of GDM or obesity, higher fat\% was associated with adverse bone health, independently of BMI. Previous research evidence shows that diabetes-induced alterations and related fractures are clinically significant and commonly underestimated problems in patients with T2D ${ }^{3,9}$. Bone fractures in high-risk women could possibly be prevented by promoting healthy lifestyle leading to reduced fat $\%$.

\section{ACKNOWLEDGEMENTS}

We would like to thank professor Johan Eriksson for providing research funding and the research facilities to conduct the bone measurements. We also thank the research nurses for their valuable work.

\section{REFERENCES}

1. Apovian M. The Obesity Epidemic--Understanding the Disease and the Treatment. N Eng J Med 2016; 374: 177-179.

2. Schmidt AM. Highlighting Diabetes Mellitus: The Epidemic Continues. Arterioscler Thromb Vasc Biol 2018; 38: e8.

3. Janghorbani M, Van Dam RM, Willett WC, et al. Systematic review of type 1 and type 2 diabetes mellitus and risk of fracture. Am J Epidemiol 2007; 166: 495-505.

4. Dede AD, Tournis S, Dontas I, et al. Type 2 diabetes mellitus and fracture risk. Metabolism 2014; 63: 1480-1490.

5. Papaioannou A, Kennedy CC, Ioannidis G, et al. The impact of incident fractures on health-related quality of life: 5 years of data from the Canadian Multicentre Osteoporosis Study. Osteoporos Int. 2009; 20: 703-714.

6. Adachi JD, Adami S, Gehlbach S, et al. Impact of prevalent fractures on quality of life: baseline results from the global longitudinal study of osteoporosis in women. Mayo Clin Proc. 2010; 85: 806-813.

7. Borgstrom F, Zethraeus N, Johnell O, et al. Costs and quality of life associated with 
osteoporosis-related fractures in Sweden. Osteoporos Int. 2006; 17: 637-650.

8. Bliuc D, Nguyen ND, Milch VE, et al. Mortality risk associated with low-trauma osteoporotic fracture and subsequent fracture in men and women. JAMA. 2009; 301: $513-521$.

9. Shanbhogue V V, Mitchell DM, Rosen CJ, et al. Type 2 diabetes and the skeleton: new insights into sweet bones. Lancet Diabetes Endocrinol. 2016; 4: 159-173.

10. Li CI, Liu CS, Lin WY, et al. Glycated Hemoglobin Level and Risk of Hip Fracture in Older People with Type 2 Diabetes: A Competing Risk Analysis of Taiwan Diabetes Cohort Study. J Bone Miner Res. 2015; 30: 1338-1346.

11. Mitama Y, Fujiwara S, Yoneda M, et al. Association of type 2 diabetes and an inflammatory marker with incident bone fracture among a Japanese cohort. J Diabetes Investig. 2017; 8: 709-715.

12. Zhu Y, Zhang C. Prevalence of Gestational Diabetes and Risk of Progression to Type 2 Diabetes: a Global Perspective. Current Diabetes Reports. 2016; 16: 7.

13. Bellamy L, Casas J-P, Hingorani AD, et al. Type 2 diabetes mellitus after gestational diabetes: a systematic review and meta-analysis. Lancet. 2009; 373: 1773-1779.

14. Kim C, Newton KM, Knopp RH. Gestational diabetes and the incidence of type 2 diabetes: a systematic review. Diabetes Care. 2002; 25: 1862-1868.

15. Tucker KL, Chen H, Hannan MT, et al. Bone mineral density and dietary patterns in older adults: the Framingham Osteoporosis Study. Am J Clin Nutr 2002; 76: 245-252.

16. Langsetmo L, Hanley DA, Prior JC, et al. Dietary patterns and incident low-trauma fractures in postmenopausal women and men aged $>/=50 \mathrm{y}$ : a population-based cohort study. Am J Clin Nutr. 2011; 93: 192-199.

17. Chastin SF, Mandrichenko O, Helbostadt JL, et al. Associations between objectivelymeasured sedentary behaviour and physical activity with bone mineral density in adults and older adults, the NHANES study. Bone. 2014; 64: 254-262.

18. Stiles VH, Metcalf BS, Knapp KM, et al. A small amount of precisely measured highintensity habitual physical activity predicts bone health in pre- and post-menopausal women in UK Biobank. Int J Epidemiol. 2017; 46: 1847-1856.

19. Vestergaard P, Mosekilde L. Fracture risk associated with smoking: a meta-analysis. J Intern Med. 2003; 254: 572-583.

20. Engberg E, Tikkanen HO, Koponen A, et al. Cardiorespiratory fitness and healthrelated quality of life in women at risk for gestational diabetes. Scand J Med Sci Sports. 2018; 28: 203-211. 
21. Harrison CL, Lombard CB, Teede HJ. Understanding health behaviours in a cohort of pregnant women at risk of gestational diabetes mellitus: an observational study. BJOG. 2012; 119: 731-738.

22. Meinila J, Koivusalo SB, Valkama A, et al. Nutrient intake of pregnant women at high risk of gestational diabetes. Food Nutr Res. 2015; 59: 26676.

23. Koivusalo SB, Rönö K, Klemetti MM, et al. Gestational Diabetes Mellitus Can Be Prevented by Lifestyle Intervention: The Finnish Gestational Diabetes Prevention Study (RADIEL): A Randomized Controlled Trial. Diabetes Care. 2016; 39: 24-30.

24. Torloni MR, Betrán AP, Horta BL, et al. Prepregnancy BMI and the risk of gestational diabetes: a systematic review of the literature with meta-analysis. Obes Rev. 2009; 10: 194-203.

25. Kim C, Berger DK, Chamany S. Recurrence of gestational diabetes mellitus: A systematic review. Diabetes Care. 2007; 30: 1314-9.

26. Nordic Nutrition Recommendations 2012 (2014). Integrating nutrition and physical activity. 5th edition. Avaialble online at: https://www.evira.fi/globalassets/vrn/pdf/nordic-nutrition-recommendations-2012.pdf. (Accessed May 25, 2019).

27. GE Healthcare Lunar 2016. X-ray Bone Densitometer with enCORE v17 software User Manual. LU43616EN Revision 18 (November 2016).

28. Hind K, Oldroyd B, Truscott J. In vivo precision of the GE Lunar iDXA densitometer for the measurement of total-body, lumbar spine, and femoral bone mineral density in adults. J Clin Densitom. 2010; 13: 413-417.

29. Rönö K, Grotenfelt NE, Klemetti MM, et al. Effect of a lifestyle intervention during pregnancy - findings from the Finnish gestational diabetes prevention trial (RADIEL). J Perinatol. 2018; 38: 1157-1164.

30. Rönö K, Stach-Lempinen B, Eriksson JG, et al. Prevention of gestational diabetes with a prepregnancy lifestyle intervention - findings from a randomized controlled trial. Int J Womens Health. 2018; 10: 493-501.

31. Rudman H, Birrel F, Pearce M, et al. Obesity, bone density relative to body weight and prevalent vertebral fracture at age 62 years: the Newcastle thousand families study. Osteoporos Int. 2019; 30: 829-836.

32. To WWK, Wong MWN. Bone mineral density changes in gestational diabetic pregnancies-a longitudinal study using quantitative ultrasound measurements of the os calcis. Gynecol Endocrinol. 2008; 24: 519-525.

33. Viljakainen HT, Valta H, Lipsanen-Nyman M, et al. Bone Characteristics and Their 
Determinants in Adolescents and Young Adults with Early-Onset Severe Obesity. Calcif Tissue Int. 2015; 97(4):364-75.

34. Raska Jr I, Raskova M, Zikan V, et al. Prevalence and Risk Factors of Osteoporosis in Postmenopausal Women with Type 2 Diabetes Mellitus. Cent Eur J Public Heal. 2017; 25: 3-10.

35. Patsch JM, Burghardt AJ, Yap SP, et al. Increased cortical porosity in type 2 diabetic postmenopausal women with fragility fractures. J Bone Miner Res. 2013; 28: 313-324.

36. Burghardt AJ, Issever AS, Schwartz A V, et al. High-resolution peripheral quantitative computed tomographic imaging of cortical and trabecular bone microarchitecture in patients with type 2 diabetes mellitus. J Clin Endocrinol Metab. 2010; 95: 5045-5055.

37. Bala Y, Zebaze R, Ghasem-Zadeh A, et al. Cortical porosity identifies women with osteopenia at increased risk for forearm fractures. J Bone Miner Res. 2014; 29: 13561362.

38. Ahmed LA, Shigdel R, Joakimsen RM, et al. Measurement of cortical porosity of the proximal femur improves identification of women with nonvertebral fragility fractures. Osteoporos Int. 2015; 26: 2137-2146.

39. Osima M, Kral R, Borgen TT, et al. Women with type 2 diabetes mellitus have lower cortical porosity of the proximal femoral shaft using low-resolution CT than nondiabetic women, and increasing glucose is associated with reduced cortical porosity. Bone. 2017; 97: 252-260.

40. Cui LH, Shin MH, Kweon SS, et al. Relative contribution of body composition to bone mineral density at different sites in men and women of South Korea. J Bone Miner Metab. 2007: 25: 165-171.

41. Lekamwasam S, Weerarathna T, Rodrigo M, et al. Association between bone mineral density, lean mass, and fat mass among healthy middle-aged premenopausal women: A cross-sectional study in southern Sri Lanka. J Bone Miner Metab. 2009; 27: 83-88

42. Janicka A, Wren TAL, Sanchez MM, et al. Fat mass is not beneficial to bone in adolescents and young adults. J Clin Endocrinol Metab. 2007; 92: 143-147.

43. Zhao LJ, Liu YJ, Liu PY, et al. Relationship of obesity with osteoporosis. J Clin Endocrinol Metab. 2007; 92: 1640-1646.

44. Yoo HJ, Park MS, Yang SJ, et al. The differential relationship between fat mass and bone mineral density by gender and menopausal status. J Bone Miner Metab. 2012; 30: 47-53.

45. Xu L, Nicholson P, Wang QJ, et al. Fat mass accumulation compromises bone adaptation to load in finnish women: A cross-sectional study spanning three 
generations. J Bone Miner Res. 2010; 25: 2341-2349.

46. Viljakainen HT, Koistinen HA, Tervahartiala T, et al. Metabolic milieu associates with impaired skeletal characteristics in obesity. PLoS One. 2017; 12: e0179660.

47. Rönö K, Stach-Lempinen B, Klemetti MM, et al. Prevention of gestational diabetes through lifestyle intervention: Study design and methods of a Finnish randomized controlled multicenter trial (RADIEL). BMC Pregnancy Childbirth. 2014; 14; 14: 70.

48. Rothney MP, Brychta RJ, Schaefer E V., et al. Body composition measured by dualenergy x-ray absorptiometry half-body scans in obese adults. Obesity. 2009; 17: 12811286. 
Table 1 Characteristics of women with and without a history of gestational diabetes $\left(n=224^{*}\right)$

\begin{tabular}{|c|c|c|c|c|}
\hline \multirow[t]{3}{*}{ Characteristic } & \multirow[t]{3}{*}{ All } & \multicolumn{2}{|c|}{ A history of gestational diabetes } & \multirow[t]{3}{*}{$P$} \\
\hline & & Yes & No & \\
\hline & & $n=146$ & $n=78$ & \\
\hline Age (years) & $40.3(4.6)$ & $41.0(4.4)$ & $39.1(4.7)$ & $0.004^{\mathrm{a}}$ \\
\hline Height (cm) & $166.5(6.4)$ & $165.9(6.2)$ & $167.5(6.6)$ & $0.082^{\mathrm{a}}$ \\
\hline Current BMI $\left(\mathrm{kg} / \mathrm{m}^{2}\right)$ & $32.2(7.0)$ & $30.7(7.3)$ & $34.9(5.7)$ & $<0.001^{\mathrm{b}}$ \\
\hline Current obesity $\left(\mathrm{BMI} \geq 30 \mathrm{~kg} / \mathrm{m}^{2}\right), \%$ & 58.5 & 47.9 & 78.2 & $<0.001^{\mathrm{c}}$ \\
\hline Fat $\%$ & $44.4(9.3)$ & $42.5(9.7)$ & $48.1(7.4)$ & $<0.001^{\mathrm{b}}$ \\
\hline $\mathrm{HbA}_{1 \mathrm{c}}(\mathrm{mmol} / \mathrm{mol})$ & $34.1(3.5)$ & $34.7(3.6)$ & $33.0(2.8)$ & $\mathbf{0 . 0 0 1}^{\mathrm{b}}$ \\
\hline Years since latest delivery & $5.4(1.8)$ & $5.6(1.7)$ & $5.1(1.8)$ & $0.052^{\mathrm{b}}$ \\
\hline Chronic disease, $\%$ & 20.5 & 20.6 & 22.1 & $0.068^{\mathrm{c}}$ \\
\hline Regular or irregular medication, $\%$ & 58.5 & 58.6 & 58.4 & $1.000^{c}$ \\
\hline Prior fracture, $\%$ & 42.5 & 41.5 & 44.2 & $0.819^{c}$ \\
\hline Osteoporosis in immediate family, $\%$ & 17.8 & 29.7 & 14.3 & $0.418^{\mathrm{c}}$ \\
\hline Current smoker, $\%$ & 11.2 & 8.3 & 16.7 & $0.095^{\mathrm{c}}$ \\
\hline Current or previous smoker, $\%$ & 17.0 & 13.8 & 23.1 & $0.116^{\mathrm{c}}$ \\
\hline $\begin{array}{l}\text { Supervised leisure-time physical } \\
\text { activity (min/day) }\end{array}$ & $5.3(9.4)$ & $5.1(8.6)$ & $5.7(10.7)$ & $0.629^{b}$ \\
\hline $\begin{array}{l}\text { Total leisure-time physical activity } \\
(\min / \text { day) }\end{array}$ & $26.2(29.6)$ & $27.6(33.8)$ & $23.7(19.6)$ & $0.638^{\mathrm{b}}$ \\
\hline Total physical activity (min/day) & $35.9(32.8)$ & $37.4(36.6)$ & $33.0(24.2)$ & $0.574^{\mathrm{b}}$ \\
\hline Leisure-time screen time (min/day) & $128.8(76.7)$ & $127.0(77.3)$ & $132.2(75.9)$ & $0.577^{\mathrm{b}}$ \\
\hline $\begin{array}{l}\text { Healthy Eating Index (HEI) (score 0-- } \\
35 \text { ) }\end{array}$ & $20.1(5.5)$ & $20.6(5.4)$ & $19.2(5.5)$ & $0.019^{b}$ \\
\hline
\end{tabular}


Data are median (SD) unless otherwise stated.

Bold values are statistically significant $(\mathrm{p}<.05)$.

$* \mathrm{n}=201-224$ depending on the variable.

${ }^{a}$ T-test.

${ }^{\mathrm{b}}$ Mann-Whitney U test.

${ }^{\mathrm{c}}$ Chi-square test.

$\mathrm{BMI}=$ body mass index $; \mathrm{HbA}_{1 \mathrm{c}}$, fat $\%=$ total body fat percentage 
Table 2 Differences in bone characteristics between women with and without a history of gestational diabetes

\begin{tabular}{llcl}
\hline Bone characteristic & A history of gestational diabetes & $P$ \\
Yes & No & \\
& $\mathrm{n}=146$ & $\mathrm{n}=78$ \\
\hline
\end{tabular}

DXA $(n=224)$

$\begin{array}{lccc}\text { Hip BMD }\left(\mathrm{g} / \mathrm{cm}^{2}\right)(\mathrm{n}=221) & 1.11(0.12) & 1.15(0.11) & \mathbf{0 . 0 3 4}^{\mathbf{a}} \\ \text { Hip BMD T-score } & 0.86(1.04) & 1.16(0.94) & \mathbf{0 . 0 3 4}^{\mathbf{a}} \\ \text { Lumbar spine (L1-L4) BMD }\left(\mathrm{g} / \mathrm{cm}^{2}\right)(\mathrm{n}=221) & 1.28(0.13) & 1.30(0.14) & 0.371^{\mathrm{a}} \\ \text { Lumbar spine T-score } & 0.94(1.09) & 1.08(1.15) & 0.371^{\mathrm{a}} \\ \text { Whole body BMD }\left(\mathrm{g} / \mathrm{cm}^{2}\right)(\mathrm{n}=222) & 1.21(0.09) & 1.25(0.09) & \mathbf{0 . 0 0 3}^{\mathbf{b}} \\ \text { Whole body BMD T-score } & 1.12(1.18) & 1.60(1.15) & \mathbf{0 . 0 0 3}^{\mathbf{b}}\end{array}$

pQCT

Distal radius $(n=224)$

$\operatorname{BMC}(\mathrm{g} / \mathrm{cm})$

$\operatorname{TotCSA}\left(\mathrm{mm}^{2}\right)$

TotDen $\left(\mathrm{mg} / \mathrm{cm}^{3}\right)$

$\operatorname{TrabDen}\left(\mathrm{mg} / \mathrm{cm}^{3}\right)$

Proximal radius $(\mathrm{n}=224)$

$\operatorname{BMC}(\mathrm{g} / \mathrm{cm})$

$\operatorname{SSIPOL}\left(\mathrm{mm}^{3}\right)$

TotCSA $\left(\mathrm{mm}^{2}\right)$

TotDen $\left(\mathrm{mg} / \mathrm{cm}^{3}\right)$

CortDen $\left(\mathrm{mg} / \mathrm{cm}^{3}\right)$
$1.11(0.16)$

$369.54(48.38)$

301.93 (41.06)

$179.80(31.98)$

$178.99(32.75)$

$0.857^{\mathrm{a}}$

$1.15(0.16) \quad 0.059^{\mathrm{b}}$

$383.01(51.50) \quad 0.053^{\mathrm{a}}$

$301.78(36.48) \quad 0.978^{\mathrm{a}}$

$1.03(0.13)$

$273.78(52.17)$

$127.61(19.76)$

$131.46(23.08)$

$0.340^{\mathrm{b}}$

$810.70(79.16)$

809.57 (75.45)

$0.989^{\mathrm{b}}$

$1168.57(30.23)$

1166.24 (32.83)

$0.530^{\mathrm{b}}$ 
Distal tibia $(\mathrm{n}=222)$

$\begin{array}{lccr}\text { BMC }(\mathrm{g} / \mathrm{cm}) & 3.21(0.47) & 3.32(0.42) & \mathbf{0 . 0 3 6}^{\mathbf{b}} \\ \text { TotCSA }\left(\mathrm{mm}^{2}\right) & 1060.08(147.69) & 1079.33(148.97) & 0.235^{\mathrm{b}} \\ & & & \\ \text { TotDen }\left(\mathrm{mg} / \mathrm{cm}^{3}\right) & 304.25(32.94) & 310.62(42.16) & 0.422^{\mathrm{b}} \\ & & & 0.947^{\mathrm{a}}\end{array}$

Diaphyseal tibia $(\mathrm{n}=221)$

$\begin{array}{lccc}\text { BMC }(\mathrm{g} / \mathrm{cm}) & 3.64(0.47) & 3.82(0.39) & \mathbf{0 . 0 0 4}^{\mathbf{a}} \\ \text { SSIPOL }(\mathrm{mm}) & 1561.46(334.57) & 1728.80(281.83) & \mathbf{0 . 0 0 1}^{\mathbf{b}} \\ \text { TotCSA }\left(\mathrm{mm}^{2}\right) & 393.28(53.07) & 418.39(47.93) & \mathbf{0 . 0 0 1}^{\mathbf{b}} \\ \text { TotDen }\left(\mathrm{mg} / \mathrm{cm}^{3}\right) & 927.17(53.09) & 916.35(54.59) & 0.155^{\mathrm{b}} \\ & & & 0.595^{\mathrm{a}} \\ \text { CortDen }\left(\mathrm{mg} / \mathrm{cm}^{3}\right) & 1192.94(21.51) & 1191.34(21.67) & \mathbf{0 . 0 0 3}^{\mathbf{a}} \\ \text { CortCSA }\left(\mathrm{mm}{ }^{2}\right) & 283.53(38.96) & 298.08(31.00) & \\ & 26.98(3.06) & 28.07(5.00) & 0.135^{\mathrm{b}}\end{array}$

Data are mean (SD).

Bold values are statistically significant $(\mathrm{p}<.05)$.

a T-test.

${ }^{\mathrm{b}}$ Mann-Whitney U test.

$\mathrm{BMC}=$ total bone mineral content BMD = bone mass density $;$ CortCSA = cortical cross-sectional area; CortDen = cortical volumetric density; DXA = dual-energy X-ray absorptiometry; SSIPOL = polar strength strain index; $\mathrm{pQCT}=$ peripheral quantitative computed tomography; TotCSA $=$ total cross-sectional area; TotDen $=$ total volumetric density; TrabDen $=$ trabecular volumetric density 
Table 3 Spearman's partial correlations between bone characteristics and health- and lifestyle-related factors. Adjusted for age, height, BMI and smoking status (n $=190-223)$

\begin{tabular}{|c|c|c|c|c|c|c|c|c|}
\hline & Fat $\%$ & $\begin{array}{l}\mathbf{H b A}_{1 \mathbf{c}} \\
(\mathrm{mmol} / \mathrm{mol})\end{array}$ & $\begin{array}{l}\text { Supervised } \\
\text { LTPA } \\
(\mathrm{min} / \mathrm{d})\end{array}$ & $\begin{array}{l}\text { Total LTPA } \\
(\mathrm{min} / \mathrm{d})\end{array}$ & $\begin{array}{l}\text { Total PA } \\
\mathrm{min} / \mathrm{d}\end{array}$ & $\begin{array}{l}\text { Screen time } \\
(\mathrm{min} / \mathrm{d})\end{array}$ & $\begin{array}{l}\text { Years since } \\
\text { last delivery }\end{array}$ & HEI \\
\hline \multirow[t]{2}{*}{ Hip BMD (g/cm2) } & -0.183 & 0.010 & 0.105 & 0.090 & 0.131 & 0.065 & -0.058 & 0.059 \\
\hline & $\mathbf{P}=\mathbf{0 . 0 0 7}$ & $\mathrm{P}=0.884$ & $\mathrm{P}=0.132$ & $\mathrm{P}=0.196$ & $P=0.062$ & $\mathrm{P}=0.350$ & $\mathrm{P}=0.410$ & $\mathrm{P}=0.411$ \\
\hline \multirow[t]{2}{*}{ Whole body BMD $\left(\mathrm{g} / \mathrm{cm}^{2}\right)$} & -0.248 & -0.065 & 0.119 & 0.091 & 0.123 & -0.010 & -0.064 & 0.030 \\
\hline & $\mathrm{P}<0.001$ & $P=0.346$ & $\mathrm{P}=0.086$ & $P=0.189$ & $\mathrm{P}=0.080$ & $\mathrm{P}=0.887$ & $P=0.359$ & $P=0.678$ \\
\hline \multicolumn{9}{|l|}{ pQCT } \\
\hline \multicolumn{9}{|l|}{ Distal radius } \\
\hline $\operatorname{TotCSA}\left(\mathrm{mm}^{2}\right)$ & $P=0.001$ & $\mathrm{P}=0.784$ & $\mathrm{P}=0.381$ & $\mathrm{P}=0.425$ & $\mathrm{P}=0.909$ & $\mathrm{P}=0.280$ & $\mathrm{P}=0.869$ & $P=0.316$ \\
\hline \multirow[t]{2}{*}{ TotDen $\left(\mathrm{mg} / \mathrm{cm}^{3}\right)$} & -0.111 & -0.011 & 0.081 & -0.015 & 0.042 & 0.019 & 0.044 & -0.039 \\
\hline & $P=0.104$ & $\mathrm{P}=0.878$ & $\mathrm{P}=0.239$ & $\mathrm{P}=0.826$ & $\mathrm{P}=0.550$ & $\mathrm{P}=0.780$ & $\mathrm{P}=0.531$ & $\mathrm{P}=0.588$ \\
\hline \multirow[t]{2}{*}{ TrabDen $\left(\mathrm{mg} / \mathrm{cm}^{3}\right)$} & -0.162 & 0.035 & 0.133 & 0.022 & 0.049 & 0.055 & 0.033 & 0.040 \\
\hline & $\mathbf{P}=\mathbf{0 . 0 1 7}$ & $P=0.604$ & $P=0.053$ & $P=0.747$ & $P=0.479$ & $\mathrm{P}=0.424$ & $P=0.633$ & $\mathrm{P}=0.578$ \\
\hline
\end{tabular}




\begin{tabular}{|c|c|c|c|c|c|c|c|c|}
\hline \multicolumn{9}{|l|}{ Proximal radius } \\
\hline \multirow[t]{2}{*}{$\mathrm{BMC}(\mathrm{g} / \mathrm{cm})$} & -0.349 & -0.052 & 0.154 & 0.097 & 0.130 & -0.023 & 0.022 & 0.051 \\
\hline & $\mathrm{P}<0.001$ & $\mathrm{P}=0.450$ & $P=0.025$ & $P=0.161$ & $P=0.062$ & $\mathrm{P}=0.743$ & $P=0.757$ & $\mathrm{P}=0.479$ \\
\hline \multirow[t]{2}{*}{ SSIPOL $\left(\mathrm{mm}^{3}\right)$} & -0.301 & -0.047 & 0.083 & 0.068 & 0.100 & -0.007 & -0.010 & 0.091 \\
\hline & $\mathrm{P}<0.001$ & $\mathrm{P}=0.494$ & $P=0.226$ & $P=0.323$ & $\mathrm{P}=0.151$ & $\mathrm{P}=0.918$ & $\mathrm{P}=0.886$ & $P=0.203$ \\
\hline \multirow[t]{2}{*}{$\operatorname{TotCSA}\left(\mathrm{mm}^{2}\right)$} & -0.354 & 0.002 & 0.091 & 0.094 & 0.103 & -0.025 & 0.037 & 0.065 \\
\hline & $\mathrm{P}<0.001$ & $\mathrm{P}=0.972$ & $\mathrm{P}=0.187$ & $\mathrm{P}=0.173$ & $\mathrm{P}=0.140$ & $\mathrm{P}=0.715$ & $\mathrm{P}=0.593$ & $P=0.366$ \\
\hline \multirow[t]{2}{*}{ TotDen $\left(\mathrm{mg} / \mathrm{cm}^{3}\right)$} & 0.048 & -0.041 & 0.036 & -0.024 & 0.028 & -0.003 & -0.006 & -0.020 \\
\hline & $\mathrm{P}=0.481$ & $\mathrm{P}=0.547$ & $P=0.605$ & $P=0.729$ & $P=0.686$ & $\mathrm{P}=0.971$ & $\mathrm{P}=0.930$ & $P=0.776$ \\
\hline \multirow[t]{2}{*}{ CortDen $\left(\mathrm{mg} / \mathrm{cm}^{3}\right)$} & 0.152 & -0.106 & -0.020 & -0.131 & -0.077 & -0.004 & 0.004 & -0.091 \\
\hline & $P=0.025$ & $P=0.120$ & $\mathrm{P}=0.771$ & $\mathrm{P}=0.058$ & $P=0.271$ & $P=0.953$ & $P=0.953$ & $P=0.204$ \\
\hline \multicolumn{9}{|l|}{ Distal tibia } \\
\hline \multirow[t]{2}{*}{$\mathrm{BMC}(\mathrm{g} / \mathrm{cm})$} & -0.361 & 0.021 & 0.264 & 0.146 & 0.160 & 0.091 & 0.035 & 0.074 \\
\hline & $\mathrm{P}<0.001$ & $P=0.769$ & $\mathrm{P}<0.001$ & $P=0.038$ & $P=0.025$ & $\mathrm{P}=0.195$ & $P=0.628$ & $\mathrm{P}=0.317$ \\
\hline \multirow[t]{2}{*}{$\operatorname{TotCSA}\left(\mathrm{mm}^{2}\right)$} & -0.242 & 0.008 & 0.094 & 0.085 & 0.103 & 0.031 & 0.067 & 0.079 \\
\hline & $\mathrm{P}<0.001$ & $\mathrm{P}=0.906$ & $\mathrm{P}=0.182$ & $P=0.227$ & $\mathrm{P}=0.150$ & $P=0.665$ & $\mathrm{P}=0.351$ & $P=0.284$ \\
\hline \multirow[t]{2}{*}{ TotDen $\left(\mathrm{mg} / \mathrm{cm}^{3}\right)$} & -0.122 & 0.018 & 0.146 & 0.037 & 0.062 & 0.100 & 0.035 & -0.020 \\
\hline & $\mathrm{P}=0.080$ & $\mathrm{P}=0.798$ & $P=0.038$ & $P=0.604$ & $\mathrm{P}=0.386$ & $\mathrm{P}=0.158$ & $P=0.627$ & $P=0.788$ \\
\hline \multirow[t]{2}{*}{ TrabDen $\left(\mathrm{mg} / \mathrm{cm}^{3}\right)$} & -0.149 & 0.027 & 0.174 & 0.021 & 0.053 & 0.150 & -0.003 & -0.021 \\
\hline & $P=0.032$ & $P=0.699$ & $P=0.013$ & $P=0.763$ & $P=0.462$ & $P=0.032$ & $P=0.969$ & $\mathrm{P}=0.780$ \\
\hline \multicolumn{9}{|l|}{ Diaphyseal tibia } \\
\hline \multirow[t]{2}{*}{$\mathrm{BMC}(\mathrm{g} / \mathrm{cm})$} & -0.330 & -0.126 & 0.216 & 0.233 & 0.224 & 0.007 & 0.019 & 0.162 \\
\hline & $\mathrm{P}<0.001$ & $\mathrm{P}=0.071$ & $P=0.002$ & $P=0.001$ & $P=0.002$ & $\mathrm{P}=0.915$ & $\mathrm{P}=0.788$ & $P=0.027$ \\
\hline SSIPOL (mm3) & -0.288 & -0.159 & 0.145 & 0.178 & 0.160 & -0.002 & 0.058 & 0.139 \\
\hline
\end{tabular}




\begin{tabular}{|c|c|c|c|c|c|c|c|c|}
\hline & $\mathrm{P}<0.001$ & $P=0.023$ & $P=0.040$ & $P=0.011$ & $P=0.024$ & $\mathrm{P}=0.972$ & $\mathrm{P}=0.419$ & $\mathrm{P}=0.059$ \\
\hline \multirow[t]{2}{*}{$\operatorname{TotCSA}\left(\mathrm{mm}^{2}\right)$} & -0.285 & -0.134 & 0.164 & 0.187 & 0.172 & -0.011 & 0.071 & 0.138 \\
\hline & $\mathrm{P}<0.001$ & $\mathrm{P}=0.056$ & $P=0.019$ & $P=0.008$ & $P=0.015$ & $\mathrm{P}=0.871$ & $\mathrm{P}=0.320$ & $\mathrm{P}=0.061$ \\
\hline \multirow[t]{2}{*}{ TotDen $\left(\mathrm{mg} / \mathrm{cm}^{3}\right)$} & -0.052 & 0.057 & 0.070 & 0.081 & 0.096 & 0.065 & -0.067 & 0.042 \\
\hline & $\mathrm{P}=0.456$ & $\mathrm{P}=0.414$ & $\mathrm{P}=0.322$ & $P=0.249$ & $\mathrm{P}=0.178$ & $P=0.356$ & $\mathrm{P}=0.344$ & $\mathrm{P}=0.565$ \\
\hline \multirow[t]{2}{*}{ CortDen $\left(\mathrm{mg} / \mathrm{cm}^{3}\right)$} & 0.030 & 0.008 & -0.093 & -0.099 & -0.090 & -0.007 & -0.007 & -0.104 \\
\hline & $P=0.667$ & $P=0.914$ & $\mathrm{P}=0.185$ & $P=0.160$ & $P=0.207$ & $P=0.926$ & $\mathrm{P}=0.924$ & $P=0.159$ \\
\hline \multirow[t]{2}{*}{ CortCSA $\left(\mathrm{mm}^{2}\right)$} & -0.340 & -0.121 & 0.237 & 0.241 & 0.236 & 0.006 & 0.017 & 0.167 \\
\hline & $\mathrm{P}<0.001$ & $\mathrm{P}=0.084$ & $P=0.001$ & $P=0.001$ & $P=0.001$ & $P=0.928$ & $\mathrm{P}=0.807$ & $\mathbf{P}=\mathbf{0 . 0 2 3}$ \\
\hline \multirow[t]{2}{*}{ CortCSA - distal TotCSA ratio } & -0.093 & -0.086 & 0.120 & 0.112 & 0.144 & 0.009 & -0.055 & 0.077 \\
\hline & $P=0.177$ & $P=0.212$ & $P=0.084$ & $P=0.108$ & $P=0.041$ & $P=0.892$ & $P=0.429$ & $P=0.286$ \\
\hline
\end{tabular}

Bold values are statistically significant $(\mathrm{p}<.05)$.

$\mathrm{BMC}=$ total bone mineral content $\mathrm{BMD}=$ bone mass density; $\mathrm{BMI}=$ body mass index; cortCSA = cortical cross-sectional area; CortDen = cortical volumetric density; $\mathrm{d}=$ day; DXA = dual-energy X-ray absorptiometry; fat $\%=$ total body fat percentage; HEI = Healthy Eating Index; LTPA = leisure-time physical activity; min = minutes; PA = physical activity; SSIPOL = polar strength strain index; $\mathrm{pQCT}=$ peripheral quantitative computed tomography; TotCSA = total cross-sectional area; TotDen = total volumetric density; TrabDen $=$ trabecular volumetric density 
Table 4 Factors independently associated with bone characteristics $(n=186-195)$

\begin{tabular}{|c|c|c|c|}
\hline Bone characteristic & Fat\% & $\begin{array}{l}\text { Supervised } \\
\text { LTPA } \\
(\mathrm{min} / \mathrm{d})\end{array}$ & HEI \\
\hline \multicolumn{4}{|l|}{ DXA } \\
\hline \multirow[t]{2}{*}{ Hip BMD (g/cm2) } & -0.144 & 0.105 & 0.055 \\
\hline & $P=0.051$ & $\mathrm{P}=0.152$ & $\mathrm{P}=0.453$ \\
\hline \multirow[t]{2}{*}{ Lumbar spine (L1-L4) BMD (g/cm²) } & -0.142 & 0.061 & 0.003 \\
\hline & $P=0.054$ & $P=0.408$ & $P=0.969$ \\
\hline \multirow[t]{2}{*}{ Whole body BMD (g/cm²) } & -0.207 & 0.078 & 0.021 \\
\hline & $P<0.005$ & $P=0.293$ & $P=0.774$ \\
\hline \multicolumn{4}{|l|}{ pQCT } \\
\hline \multicolumn{4}{|l|}{ Distal radius } \\
\hline \multirow[t]{2}{*}{$\mathrm{BMC}(\mathrm{g} / \mathrm{cm})$} & -0.328 & 0.064 & 0.032 \\
\hline & $P<0.001$ & $\mathrm{P}=0.386$ & $P=0.666$ \\
\hline \multirow[t]{2}{*}{$\operatorname{TotCSA}\left(\mathrm{mm}^{2}\right)$} & -0.238 & 0.007 & 0.073 \\
\hline & $P=0.001$ & $\mathrm{P}=0.292$ & $\mathrm{P}=0.320$ \\
\hline \multirow[t]{2}{*}{ TotDen $\left(\mathrm{mg} / \mathrm{cm}^{3}\right)$} & -0.104 & 0.035 & -0.047 \\
\hline & $P=0.159$ & $\mathrm{P}=0.631$ & $\mathrm{P}=0.519$ \\
\hline \multirow[t]{2}{*}{ TrabDen $\left(\mathrm{mg} / \mathrm{cm}^{3}\right)$} & -0.146 & 0.103 & 0.038 \\
\hline & $P=0.046$ & $P=0.162$ & $P=0.610$ \\
\hline \multicolumn{4}{|l|}{ Proximal radius } \\
\hline \multirow[t]{2}{*}{$\mathrm{BMC}(\mathrm{g} / \mathrm{cm})$} & -0.310 & 0.046 & 0.031 \\
\hline & $P<0.001$ & $\mathrm{P}=0.534$ & $\mathrm{P}=0.673$ \\
\hline \multirow[t]{2}{*}{$\operatorname{SSIPOL}\left(\mathrm{mm}^{3}\right)$} & -0.285 & -0.004 & 0.068 \\
\hline & $\mathrm{P}<0.001$ & $\mathrm{P}=0.953$ & $P=0.357$ \\
\hline \multirow[t]{2}{*}{$\operatorname{TotCSA}\left(\mathrm{mm}^{2}\right)$} & -0.336 & -0.021 & 0.041 \\
\hline & $\mathrm{P}<0.001$ & $P=0.774$ & $P=0.573$ \\
\hline \multirow[t]{2}{*}{ TotDen $\left(\mathrm{mg} / \mathrm{cm}^{3}\right)$} & 0.064 & 0.044 & -0.008 \\
\hline & $P=0.387$ & $P=0.551$ & $P=0.915$ \\
\hline \multirow[t]{2}{*}{ CortDen $\left(\mathrm{mg} / \mathrm{cm}^{3}\right)$} & 0.141 & -0.014 & -0.076 \\
\hline & $\mathrm{P}=0.055$ & $\mathrm{P}=0.850$ & $\mathrm{P}=0.299$ \\
\hline \multicolumn{4}{|l|}{ Distal tibia } \\
\hline \multirow[t]{2}{*}{$\mathrm{BMC}(\mathrm{g} / \mathrm{cm})$} & -0.287 & 0.192 & 0.076 \\
\hline & $\mathrm{P}<0.001$ & $P<0.009$ & $P=0.303$ \\
\hline
\end{tabular}




\begin{tabular}{|c|c|c|c|}
\hline \multirow[t]{2}{*}{ TotCSA $\left(\mathrm{mm}^{2}\right)$} & -0.261 & 0.072 & 0.071 \\
\hline & $\mathrm{P}<0.001$ & $P=0.342$ & $P=0.344$ \\
\hline \multirow[t]{2}{*}{ TotDen $\left(\mathrm{mg} / \mathrm{cm}^{3}\right)$} & -0.066 & 0.106 & -0.031 \\
\hline & $P=0.379$ & $P=0.160$ & $P=0.683$ \\
\hline \multirow[t]{2}{*}{ TrabDen $\left(\mathrm{mg} / \mathrm{cm}^{3}\right)$} & -0.102 & 0.156 & -0.030 \\
\hline & $P=0.176$ & $\mathbf{P}=\mathbf{0 . 0 3 7}$ & $P=0.689$ \\
\hline \multicolumn{4}{|l|}{ Diaphyseal tibia } \\
\hline \multirow[t]{2}{*}{$\mathrm{BMC}(\mathrm{g} / \mathrm{cm})$} & -0.303 & 0.127 & 0.148 \\
\hline & $\mathrm{P}<0.001$ & $P=0.091$ & $P=0.048$ \\
\hline \multirow[t]{2}{*}{ SSIPOL (mm3) } & -0.272 & 0.063 & 0.120 \\
\hline & $\mathrm{P}<0.001$ & $P=0.401$ & $\mathrm{P}=0.110$ \\
\hline \multirow[t]{2}{*}{ TotCSA $\left(\mathrm{mm}^{2}\right)$} & -0.264 & 0.089 & 0.123 \\
\hline & $\mathrm{P}<0.001$ & $P=0.239$ & $P=0.101$ \\
\hline \multirow[t]{2}{*}{ TotDen $\left(\mathrm{mg} / \mathrm{cm}^{3}\right)$} & -0.023 & 0.040 & 0.051 \\
\hline & $P=0.762$ & $P=0.596$ & $P=0.503$ \\
\hline \multirow[t]{2}{*}{ CortDen $\left(\mathrm{mg} / \mathrm{cm}^{3}\right)$} & 0.014 & -0.115 & -0.113 \\
\hline & $P=0.857$ & $\mathrm{P}=0.126$ & $P=0.134$ \\
\hline \multirow[t]{2}{*}{ CortCSA $\left(\mathrm{mm}^{2}\right)$} & -0.299 & 0.145 & 0.156 \\
\hline & $\mathrm{P}<0.001$ & $\mathrm{P}=0.053$ & $P=\mathbf{0 . 0 3 8}$ \\
\hline \multirow[t]{2}{*}{ CortCSA - distal TotCSA ratio } & -0.039 & 0.060 & 0.065 \\
\hline & $P=0.598$ & $\mathrm{P}=0.418$ & $\mathrm{P}=0.378$ \\
\hline
\end{tabular}

Bold values are statistically significant $(\mathrm{p}<.05)$

Spearman's partial correlations adjusted for age, height, BMI, smoking status, $\mathrm{HbA}_{\mathrm{lc}}$, screen time, total body fat percentage, supervised leisure-time physical activity and Healthy Eating Index.

$\mathrm{BMC}=$ total bone mineral content BMD = bone mass density $;$ cortCSA = cortical cross-sectional area; CortDen = cortical volumetric density; $\mathrm{d}=$ day; DXA = dual-energy X-ray absorptiometry; fat $\%=$ total body fat percentage HEI = Healthy Eating Index LTPA = leisure-time physical activity; min = minutes; PA = physical activity; SSIPOL = polar strength strain index; $\mathrm{pQCT}=$ peripheral quantitative computed tomography; TotCSA $=$ total cross-sectional area; TotDen $=$ total volumetric density; TrabDen = trabecular volumetric density 